Calcineurin inhibitors $(\mathrm{Cl})$, such as tacrolimus and cyclosporin A (CSA), are routinely used for prophylaxis and therapy of graft-versus-host disease (GVHD) after haematopoietic stem cell transplantation (HSCT) and solid organ transplantation. Neurotoxicity is a well-known side effect of calcineurin inhibitor therapy with multifactorial pathogenesis. In this paper we report the clinical and radiological features of $\mathrm{Cl}$-induced cerebral complications in four paediatric patients after haematopoietic stem cell transplantation. The most common symptoms in this series of patients were seizures and disturbances of consciousness. Abnormalities in neuroimaging suggested $\mathrm{Cl}$-induced leukoencephalopathy or reversible posterior leukoencephalopathy syndrome or showed cerebral haemorrhage. Other possible causes of neurological complications, such as delayed cyclosporin A toxicity, posttransplant microangiopathy, hypertension or thrombocytopenia are discussed. We also present a review of the literature of tacrolimus-induced neurotoxicity in children. So far, 47 case reports of children and adolescents up to 21 years of age with tacrolimus-induced encephalopathy have been described in the literature. The clinical features of tacrolimus-induced leukoencephalopathy in children are similar to those reported in adults.

Key words: calcineurin inhibitors, tacrolimus, cyclosporin A, cerebral complications, reversible posterior leukoencephalopathy syndrome, children.

\section{Cerebral complications induced by calcineurin inhibitors in children after haematopoietic stem cell transplantation}

\author{
Magdalena Piątkowska ${ }^{12}$, Mariusz Wysocki ${ }^{13}$, Jan Styczyński ${ }^{13}$
}

1Department of Paediatric Haematology and Oncology, Collegium Medicum, Nicolaus Copernicus University, Bydgoszcz, Poland

2Department of Chemotherapy, Centre of Oncology, Bydgoszcz, Poland 3University Hospital no. 1, Collegium Medicum, Nicolaus Copernicus University, Bydgoszcz, Poland

\section{Introduction}

Tacrolimus (FK506) is a fungal metabolite produced by Streptomyces tsukubaensis, discovered in 1984 [1]. This macrolide lactone immunosuppressant is an effective agent used in preventing acute and chronic graftversus-host disease (GVHD) after haematopoietic stem cell transplantation (HSCT), and in solid organ transplant recipients in order to prevent graft rejection [2, 3]. Tacrolimus produces various effects which include inhibition of calcineurin, and is used as a therapeutic alternative to cyclosporin [4]. Major adverse effects of tacrolimus include nephrotoxicity, neurotoxicity, glucose intolerance, hypertension, diarrhoea, and electrolyte imbalance [5].

Cyclosporin A (CSA) is a calcineurin inhibitor routinely used as GVHD prophylaxis after HSCT. Common CSA-related side-effects include renal dysfunction, arterial hypertension, hepatic toxicity, gingival hyperplasia, hypertrichosis, opportunistic infections and tremors [6]. CSA neurotoxicity occurs in less than $5 \%$ of patients after renal and bone marrow transplantation [7]. Unfortunately, neurotoxicity can occur both at therapeutic and at high CSA levels [6].

Neurological side effects from calcineurin inhibitors are mostly mild and transient, and include headaches, dysarthria, visual changes, insomnia, photophobia, nightmares, hyperesthesia and postural tremor. More severe side effects may include psychosis, akinetic mutism, expressive aphasia, opisthotonus with severe rigidity, cortical blindness and seizures. Neurotoxicity is more common early after initiation of tacrolimus therapy. However, it may occur months or even years later $[5,8]$.

Reversible posterior leukoencephalopathy syndrome (RPLS) is a neurological syndrome characterized by subcortical white matter lesions seen on magnetic resonance imaging with particular involvement of the posterior cerebral hemispheres. Neurological symptoms usually resolve after the drug is withdrawn [9]. MRI images often show atypical findings, some of them irreversible. Despite clinical and radiological evidence of recovery, a significant number of patients develop epilepsy [10].

Allogeneic HSCT is an effective therapy in various haematopoietic malignancies. However, the risk of developing acute or chronic GVHD remains one of the major transplant complications [11]. Acute GVHD occurs within the first 100 days after bone marrow transplantation and its predominant symptoms affect the skin, liver, and intestine. Chronic GVHD occurs beyond day 100 after HSCT; its symptoms can affect all organs [12, 13]. We hereby present four patients after HSCT who received tacrolimus therapy for acute or chronic GVHD and developed cerebral complications. 


\section{Case reports}

Patient 1, a 12-year-old boy diagnosed with AML M2. After relapse, he received matched sibling donor $\mathrm{HSCT}$, and no symptoms of acute or chronic GVHD were observed. After the second relapse, he was treated with non-myeloablative therapy (low-dose cytarabine, fludarabine, and idarubicin) and G-CSF-mobilized donor blood cells transplantation (MDBCT) without immunosuppression. Ten days later, he presented skin and gut acute GVHD grade III/IV but was in good general condition and in remission of AML. He was treated with glucocorticosteroids and CSA. Because of the steroid resistance and progression of acute GVHD, anti-thymocyte globulin was administered. Due to a poor response, CSA was switched to intravenous tacrolimus, 4 mg daily from day +85 up to day +88 when he presented with leftsided hemiplegia and aphasia. CT scan showed intracerebral haemorrhages in both frontal and parietal lobes, and in the lateral ventricle (Fig. 1 A, B). His blood pressure, as well as platelet count and coagulation profile, were within normal range values. The tacrolimus therapy was withdrawn. The patient died on day +90 from multiorgan failure.

Patient 2, a 10-year-old girl diagnosed with Ph-positive ALL, who received HSCT and achieved complete remission. On day +150 , two weeks after CSA withdrawal, she presented with late-onset acute GVHD of the skin, fast progressing to grade IV. The girl was treated with glucocorticosteroids, CSA and mycophenolate mofetil. Due to a poor response, CSA was withdrawn, and from day +176 she was treated with tacrolimus intravenously starting at a daily dose of $4 \mathrm{mg}$ and adjusting to a trough value of $10-20 \mathrm{ng} / \mathrm{ml} \mathrm{up}$ to day +204 , when she presented with focal, secondarily generalized seizures and right-sided choreal involuntary movements. MRI revealed high-intensity areas in the white substance, which were diagnosed as leukoencephalopathy

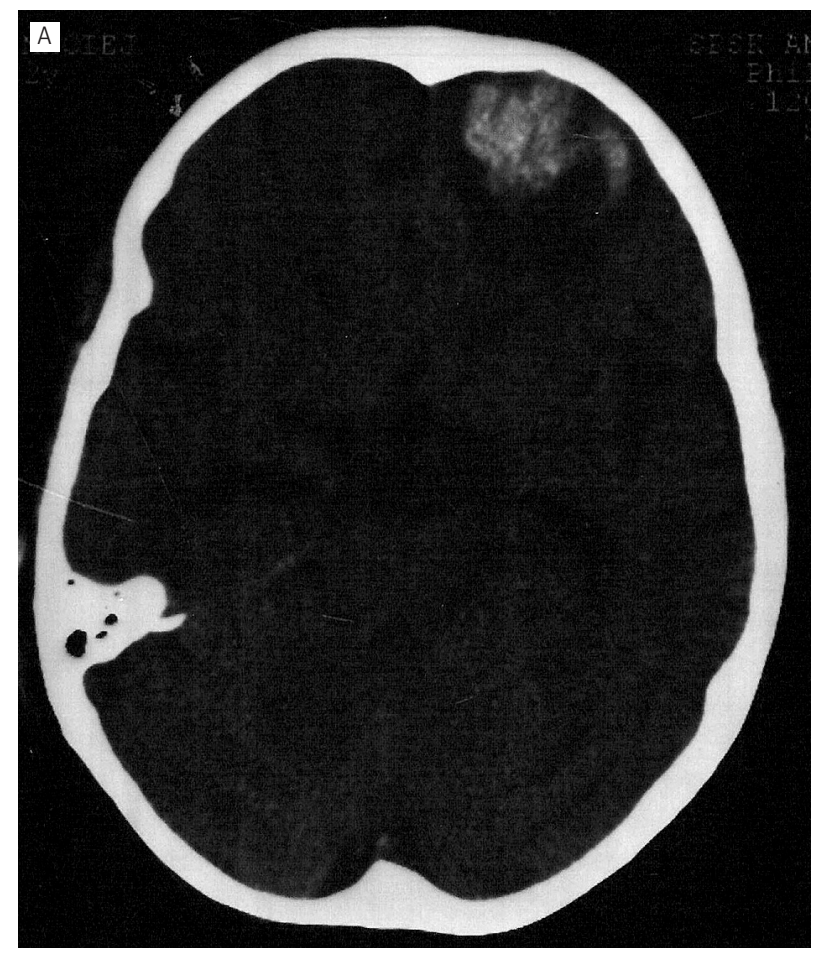

(Fig. 2 A, B). Her blood pressure, platelet count and coagulation profile were normal. A lumbar puncture was not performed. The girl died on day +216 after HSCT from cerebral insufficiency, without any neurological improvement. An autopsy was not performed.

Patient 3, a 12-year-old girl diagnosed with Ph-positive ALL, who received HSCT from an unrelated donor. Starting from day +17 , she presented with skin GVHD and was treated with glucocorticosteroids, CSA and mycophenolate mofetil. Her blood pressure was controlled by hypotensive drugs and was within normal values. Her platelet count was low, and she required platelet transfusions, usually once a week. Due to a poor response, CSA was switched to oral tacrolimus from day +216 , starting from a daily dose of $6 \mathrm{mg}$ tapering to $3 \mathrm{mg}$ up to day +233 , when loss of consciousness and generalized seizures were observed. T2WI and FLAIR sequence MRI revealed high-intensity areas subcortically, in the frontoparietal borderline on both sides, as well as cortico-subcortically, in posterior parts of occipital lobes and medial parts of parietal lobes. The ventricular system was insignificantly widened, although without translocation. The representation and location of changes in MRI suggested reversible posterior leukoencephalopathy syndrome (RPLS). CT did not show any cerebral haemorrhage. The patient died on day +248 after HSCT from cerebral insufficiency.

Patient 4, a 4-year-old boy diagnosed with chronic myeloid leukaemia who received HSCT from an unrelated donor. On day +136 , he developed symptoms of gut GVHD and thrombocytopenia, but he did not require platelet transfusions. The boy was treated with glucocorticosteroids, CSA and mycophenolate mofetil. His blood pressure was normal. Due to a poor response, CSA was switched on day +175 to oral tacrolimus, $3 \mathrm{mg}$ a day up to day +181 , when he pre-

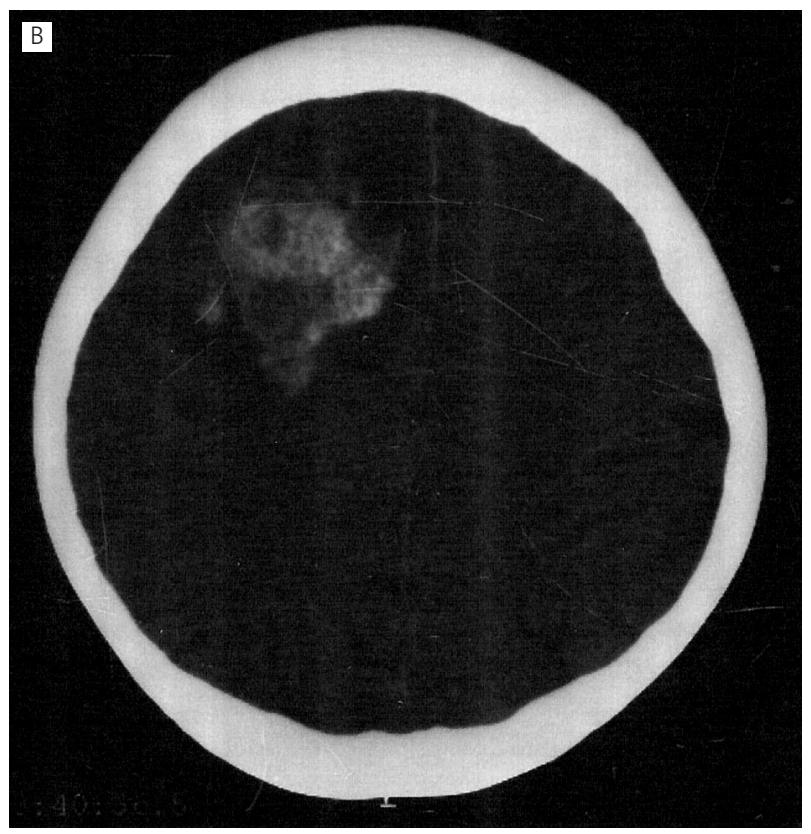

Fig. $1 \mathrm{~A}, \mathrm{~B}$. CT brain changes in patient 1 

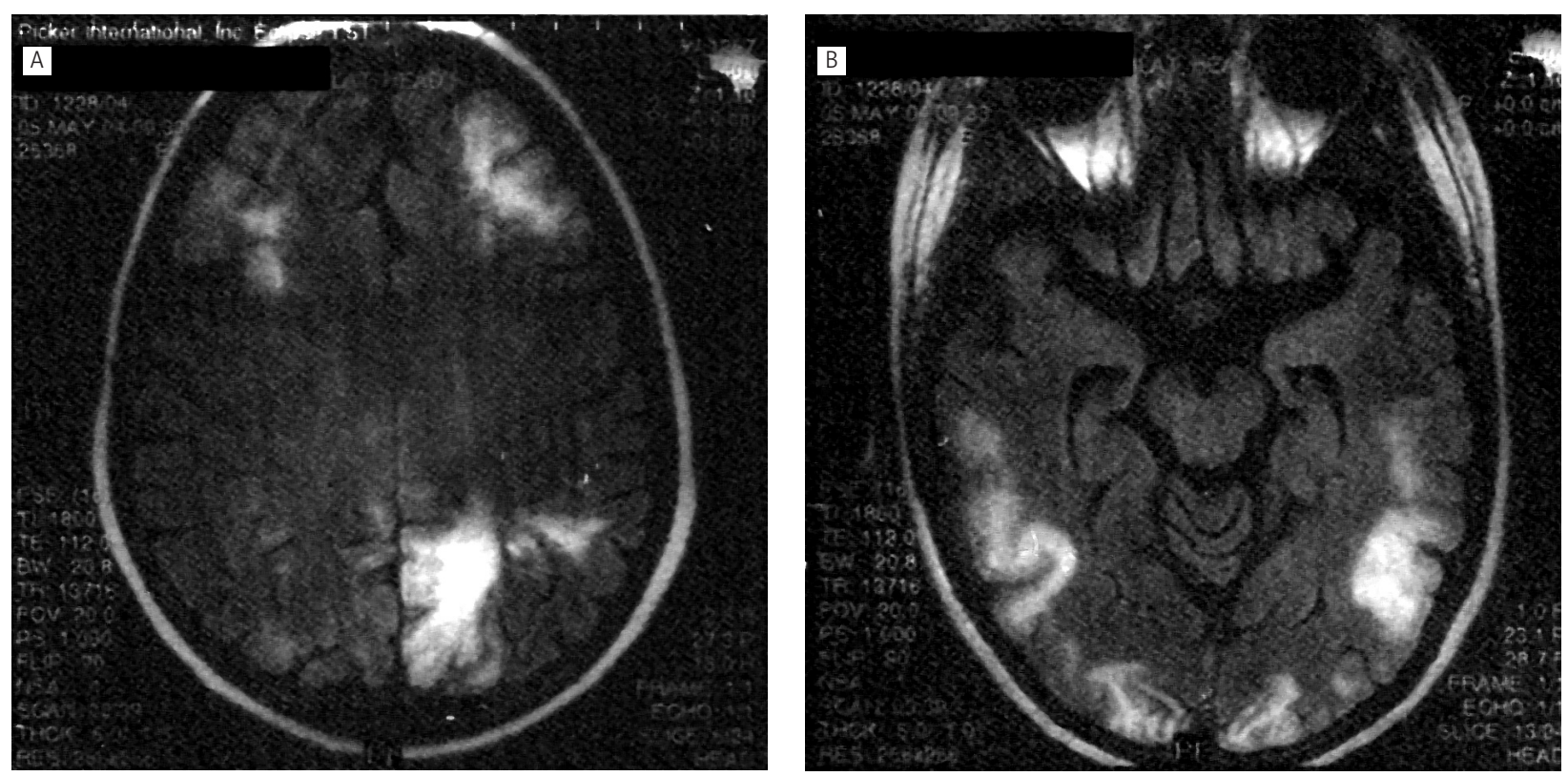

Fig. 2 A, B. MRI brain changes in patient 2

sented with consciousness disturbances and dyspnoea. CT did not show any cerebral haemorrhage. On day +185 , he presented with clinical symptoms of focal neurological deficit such as right-sided hemiplegia, seizures and strabismus. EEG taken on day +188 showed unorganized activity with the deficit being more visible on the left side. The patient died on day +189 from cerebral insufficiency.

In all patients, the dose of tacrolimus was adjusted to maintain blood levels between 10 and $20 \mathrm{ng} / \mathrm{ml}$. The serum creatinine, aminotransferases, sodium, potassium, magnesium and cholesterol levels were normal. As a treatment for chronic GVHD, all patients received methylprednisolone in a dose of $1 \mathrm{mg} / \mathrm{kg} /$ day.

\section{Discussion}

Neurotoxicity is a well-known side effect of tacrolimus therapy. However, the reversible posterior leukoencephalopathy syndrome is a rather rare complication. In 1996, Hinchey et al. described the first series of 15 patients with RPLS [14]. The clinical symptoms included headaches, vomiting, confusion, seizures, cortical blindness and motor signs. In these patients, neuroimaging showed extensive bilateral white matter abnormalities, suggestive of oedema, especially in the parieto-occipital regions of the cerebral hemispheres. The syndrome was documented to be reversible, as the neurological deficits resolved within two weeks from treatment with antihypertensives, withdrawal of the immunosuppressive therapy, or reduction of the dose [14].

As far as the pathogenesis of tacrolimus-related encephalopathy is concerned, several factors should be considered $[15,16]$. The toxic effects of tacrolimus have not been defined yet, but a direct neurotoxicity may be the cause of the white matter oedema [17]. The drug may have a direct neurotoxic effect, disrupting the blood-brain barrier, or deregulate the cerebrovascular system [14, 17]. The occipital white matter is particularly vulnerable to the neurotox- ic effects of tacrolimus. It should be noted that calcineurin inhibition modifies sympathetic outflow, which may mediate neurotoxic and hypertensive adverse events [17]. There are several risk factors that increase the probability of development of RPLS, such as advanced liver failure, hypertension, antineoplastic drugs, steroids, irradiation, infections, hypocholesterolaemia, elevated tacrolimus blood levels and hypomagnesaemia $[14,16,17]$.

Refractory GVHD and a sudden increase of blood pressure seem to be predisposing factors of tacrolimus-related encephalopathy. Furthermore, it is well known that hypertension itself causes encephalopathy, while it is frequently observed after SCT and may result from administration of tacrolimus and/or steroids, as well as from the impairment of renal function. Since the reduction and withdrawal of the drug or switching to less potent anti-GVHD agents usually results in worsening of the GVHD, during the administration of tacrolimus drug serum levels and blood pressure should be controlled [16]. In the first place, however, discontinuation of tacrolimus therapy should be seriously considered. For a short period, tacrolimus may be replaced with mycophenolate mofetil, and then restarted, with appropriate reduction of dosage. There are also drugs, such as erythromycin, danazol, and fluconazole, that may increase levels of immunosuppressive agents and trigger neurotoxicity. In two large studies, patients with tacrolimus neurotoxicity were switched to cyclosporin, and vice versa. Resolution of neurotoxicity was observed in nearly all cases. Surprisingly, there was no recurrence of neurotoxicity after restarting the treatment $[7,18,19]$.

So far, 47 case reports of children and adolescents up to 21 years of age with tacrolimus-induced encephalopathy have been described in the literature (Table 1). The clinical features of tacrolimus-induced leukoencephalopathy in children are similar to those reported in adults [15].

Tacrolimus is known to induce encephalopathy in approximately $5 \%$ of patients receiving it after solid organ trans- 
Table 1.

\begin{tabular}{|c|c|c|c|c|c|c|}
\hline References & $\begin{array}{c}\text { Number } \\
\text { of patients with } \\
\text { neurotoxicity }\end{array}$ & $\begin{array}{l}\text { Recovery/ } \\
\text { improvement }\end{array}$ & Death & Therapy & $\begin{array}{c}\text { Commonly } \\
\text { observed } \\
\text { symptoms/complaints }\end{array}$ & $\begin{array}{l}\text { Abnormality on } \\
\text { neuroimages/EEG }\end{array}$ \\
\hline [15] & 4 & 3 & 1 & $\begin{array}{l}\text { prevention } \\
\text { of rejection SOT } \\
\text { recipients }\end{array}$ & seizures & $\begin{array}{l}\text { parieto-occipital } \\
\text { white matter lesions } \\
\text { and atrophy }\end{array}$ \\
\hline [16] & 10 & 6 & 4 & $\begin{array}{c}\text { prevention } \\
\text { of GVHD after SCT }\end{array}$ & $\begin{array}{c}\text { convulsions, } \\
\text { drowsiness, } \\
\text { headache, nausea, } \\
\text { cortical blindness, } \\
\text { hypertension }\end{array}$ & $\begin{array}{c}\text { high-intensity } \\
\text { lesions in white } \\
\text { matter on MRI } \\
\text { T2-weighted or } \\
\text { fluid-attenuated } \\
\text { inversion recovery images }\end{array}$ \\
\hline [20] & 15 & 15 & 0 & $\begin{array}{l}\text { prevention of GVHD } \\
\text { after alloBMT }\end{array}$ & tremors/seizures & MRI/CT scan - negative \\
\hline [21] & 3 & 2 & 1 & $\begin{array}{c}\text { prevention of GVHD } \\
\text { after SCT }\end{array}$ & $\begin{array}{l}\text { disorientation and } \\
\text { leukoencephalopathy }\end{array}$ & $\begin{array}{c}\text { cerebral } \\
\text { haemorrhage in CT scan }\end{array}$ \\
\hline [22] & 2 & 2 & 0 & $\begin{array}{l}\text { prevention of GVHD } \\
\text { after MUD CBT }\end{array}$ & tremors & no data \\
\hline [23] & 1 & 0 & 1 & $\begin{array}{l}\text { prevention of GVHD } \\
\text { after alloBMT }\end{array}$ & $\begin{array}{l}\text { CSA/FK506-related } \\
\text { encephalopathy with } \\
\text { cerebral haemorrhagic } \\
\text { infarction, hypertension, } \\
\text { respiratory failure }\end{array}$ & no data \\
\hline [24] & 2 & No data & 0 & $\begin{array}{l}\text { prevention of rejection } \\
\text { in orthotopic liver } \\
\text { transplant recipients }\end{array}$ & no data & no data \\
\hline [25] & 1 & No data & No data & $\begin{array}{l}\text { prevention of rejection } \\
\text { in renal transplant } \\
\text { recipients }\end{array}$ & $\begin{array}{l}\text { seizures, malignant } \\
\text { hypertension }\end{array}$ & no data \\
\hline [26] & 5 & 3 & 0 & $\begin{array}{l}\text { prevention of rejection } \\
\text { in renal, liver or bone } \\
\text { marrow transplant } \\
\text { recipients }\end{array}$ & $\begin{array}{l}\text { occipital seizures, } \\
\text { hypertension, low } \\
\text { conscience (PLS) }\end{array}$ & $\begin{array}{c}\text { occipital seizures } \\
\text { or status EEG, } \\
\text { in neuroimaging - oedema } \\
\text { lesions in posterior regions }\end{array}$ \\
\hline [27] & 4 & 4 & 0 & $\begin{array}{l}\text { no data } \\
\text { headache, clouding } \\
\text { of sensorium (PLS) }\end{array}$ & seizures & $\begin{array}{l}\text { lesions in the white } \\
\text { and grey matter in MRI }\end{array}$ \\
\hline
\end{tabular}

plantation or bone marrow transplantation [16]. The authors observed neurotoxicity in $7 \%$ to $37 \%$ of patients receiving tacrolimus therapy. In other presented reports, only patients with neurotoxicity were described. There were several commonly observed symptoms and complaints, such as convulsions, seizures, drowsiness, low consciousness, hypertension, headache, nausea and cortical blindness. Abnormalities on neuroimaging seemed to be typical for tacrolimus-induced leukoencephalopathy. In some cases, however, there is no information on this matter. Recovery or improvement was observed in most presented cases.

The most common symptoms in our patients were seizures and consciousness disturbances. Abnormalities in neuroimaging suggested tacrolimus-induced leukoencephalopathy or showed cerebral haemorrhage. All the patients died. Also, in all the cases neurological symptoms were observed shortly after starting tacrolimus therapy. It is not definite that these symptoms were related to tacrolimus therapy; they might have been the delayed effect of cyclosporin that had been administered earlier. The other possible cause of the neurological symptoms, particularly in the patient who showed no changes in CT scan, could be the post-transplant microangiopathy.

To sum up, neurotoxicity is one of the major side effects of calcineurin inhibitors $(\mathrm{Cl})$ that clinicians should certainly be aware of. If any of the symptoms develop, such as seizures or consciousness disturbances, diagnostic procedures need to be performed, of which neuroimaging seems to be especially important. The treatment is to stop the administration of the drug or decrease the dose and lower the blood pressure if raised.

It is crucial to increase awareness of neurotoxicity proneness in certain patients. These patients should be treated with particular consideration as a high-risk group for undesirable tacrolimus-driven complications. As far as the future clinical care is concerned, high-risk patients should be care- 
fully monitored for potential neurotoxic side effects. All transplant centres should make an effort to promote studies on after-transplant complications, as well as on their risk factors.

\section{References}

1. Kino T, Hatanaka H, Hashimoto $M$, et al. FK-506, a nove immunosuppressant isolated from a Streptomyces. I. Fermentation, isolation, and physico-chemical and biological characteristics. J Antibiot (Tokyo) 1987; 40: 1249-55.

2. Schreiber SL, Crabtree GR. The mechanism of action of cyclosporin A and FK506. Immunol Today 1992; 13: 136-42.

3. Woo M, Przepiorka D, Ippoliti C, et al. Toxicities of tacrolimus and cyclosporin A after allogeneic blood stem cell transplantation. Bone Marrow Transplant 1997; 20: 1095-8.

4. Plosker GL, Foster RH. Tacrolimus: a further update of its pharmacology and therapeutic use in the management of organ transplantation. Drugs 2000; 59: 323-89.

5. Staatz CE, Taylor PJ, Lynch SV, Tett SE. A pharmacodynamic investigation of tacrolimus in pediatric liver transplantation. Liver Transpl 2004; 10: 506-12.

6. Noe A, Cappelli B, Biffi A, et al. High incidence of severe cyclosporine neurotoxicity in children affected by haemoglobinopaties undergoing myeloablative haematopoietic stem cell transplantation: early diagnosis and prompt intervention ameliorates neurological outcome. Ital J Pediatr 2010; 36: 14

7. Wijdicks EF. Neurotoxicity of immunosuppressive drugs. Liver Transpl 2001; 7: 937-42

8. Junna MR, Rabinstein AA. Tacrolimus induced leukoencephalopathy presenting with status epilepticus and prolonged coma. J Neurol Neurosurg Psychiatry 2007; 78: 1410-1.

9. Fruhauf NR, Koeppen Dagger S, Saner FH, et al. Late onset of tacrolimus-related posterior leukoencephalopathy after living donor liver transplantation. Liver Transpl 2003; 9: 983-5.

10. Morris EB, Laningham FH, Sandlund JT, Khan RB. Posterior reversible encephalopathy syndrome in children with cancer. Pediatr Blood Cancer 2007; 48: 152-9.

11. Nash RA, Pineiro LA, Storb R, et al. FK506 in combination with methotrexate for the prevention of graft-versus-host disease after marrow transplantation from matched unrelated donors. Blood 1996; 88: 3634-41.

12. Iwasaki T. Recent advances in the treatment of graft-versus-host disease. Clin Med Res 2004; 2: 243-52.

13. Deeg HJ. How I treat refractory acute GVHD. Blood 2007; 109: 4119-26.

14. Hinchey J, Chaves C, Appignani B, et al. A reversible posterior leukoencephalopathy syndrome. N Engl J Med 1996; 334: 494-500.

15. Torocsik HV, Curless RG, Post J, et al. FK506-induced leukoencephalopathy in children with organ transplants. Neurology 1999; 52: 1497-500.

16. Kanekiyo T, Hara J, Matsuda-Hashii Y, et al. Tacrolimus-related encephalopathy following allogeneic stem cell transplantation in children. Int J Hematol 2005; 81: 264-8.

17. Kaleyias J, Faerber E, Kothare SV. Tacrolimus induced subacute cerebellar ataxia. Eur J Paediatr Neurol 2006; 10: 86-9.

18. Jain A, Brody D, Hamad I, et al. Conversion to neoral for neurotoxicity after primary adult liver transplantation under tacrolimus. Transplantation 2000; 69: 172-6.

19. Emre S, Genyk Y, Schluger LK, et al. Treatment of tacrolimus-related adverse effects by conversion to cyclosporine in liver transplan recipients. Transpl Int 2000; 13: 73-8.

20. Yanik G, Levine JE, Ratanatharathorn V, et al. Tacrolimus (FK506) and methotrexate as prophylaxis for acute graft-versus-host disease in pediatric allogeneic stem cell transplantation. Bone Marrow Transplant 2000; 26: 161-7.

21. Osunkwo I, Bessmertny O, Harrison L, et al. A pilot study of tacrolimus and mycophenolate mofetil graft-versus-host disease prophylaxis in childhood and adolescent allogeneic stem cell transplant recipients. Biol Blood Marrow Transplant 2004; 10: 246-58.
22. Soni S, Hente M, Breslin N, et al. Combined tacrolimus (FK-506) and mycophenolate mofetil (MMF) for graft-versus-host disease (GVHD) prophylaxis in children undergoing cord blood transplantation (CBT). Biology of Blood and Marrow Transplantation 2007; 13: 66.

23. Mori A, Tanaka J, Kobayashi S, et al. Fatal cerebral hemorrhage associated with cyclosporin-A/FK506-related encephalopathy after allogeneic bone marrow transplantation. Ann Hematol 2000; 79: 588-92.

24. Colombani PM, Lau H, Prabhakaran K, et al. Cumulative experience with pediatric living related liver transplantation. J Pediatr Surg 2000; 35: 9-12.

25. Neu AM, Furth SL, Case BW, et al. Evaluation of neurotoxicity in pediatric renal transplant recipients treated with tacrolimus (FK506). Clin Transplant 1997; 11: 412-4.

26. Lara N, Pascual I. Partial occipital seizures as main symptom of posterior encephalopathy secondary to immunosuppresants. Neurologia 2006; 21: 269-74.

27. Hernandez Ch M, Nunez FA, Mesa LT, et al. Reversible posterior leukoencephalopathy syndrome in patients with immunosuppressive treatment: report of four cases. Rev Med Chil 2008; 136: 93-8.

\section{Address for correspondence}

\section{Jan Styczyński MD}

Department of Paediatric Haematology and Oncology

ul. Curie-Skłodowskiej 9

85-094 Bydgoszcz, Poland

tel. +48525854860

$\mathrm{fax}+48525854867$

e-mail: jstyczynski@cm.umk.pl 